\title{
Đánh giá mức độ ô nhiễm vi sinh vật trong sản phẩm thịt dã chế biến tại một số chợ khu vực nam sông Hương thành phố Huế
}

\author{
Tôn Thất Nhuận Thân ${ }^{1^{*}}$, Ngô Thị Tuyết Mai', Phạm Thị Ngọc Lan ${ }^{2}$ \\ ${ }^{1}$ Trung tâm Kiêm nghiệm Thuốc, Mỹ phẩm, Thực phẩm Thửa Thiên Huế, Việt Nam \\ ${ }^{2}$ Trường Đại học Khoa học, Đại học Huế, Việt Nam
}

(Ngày đến tòa soạn: 14/12/2020; Ngày chấp nhận đăng: 24/02/2020)

\section{Tóm tắt}

Sản phẩm thịt đã chế biến là một trong những loại thực phẩm xuất hiện phổ biến và ngày càng nhiêu trong bữa ăn hàng ngày của người tiêu dùng. Vì vậy, việc đánh giá mức độ ô nhiễm vi sinh vật trong sản phẩm thịt đã chế biến tại các chợ sẽ cung cấp thêm thông tin về tình trạng nhiễm khuẩn cho các cơ quan quản lý an toàn vệ sinh thực phẩm và người tiêu dùng. Chúng tôi đã khảo sát tình hình ô nhiễm vi sinh vật đối với sản phẩm thịt đã chế biến tại một số chợ ở khu vực Nam sông Hương thành phố Huế với 90 mẫu được phân tích thuộc 03 nhóm là thịt lên men, thịt đóng gói và thịt không đóng gói. Kết quả cho thấy, $100 \%$ mẫu đều nhiễm tổng số vi sinh vật hiếu khí, Coliforms và Escherichia coli, trong đó $100 \%$ mẫu Coliforms và E. coli không đạt tiêu chuẩn của Bộ Y tế. Số lượng vi sinh vật hiếu khí dao động từ $2,7 \times 10^{3}-2,8 \times 10^{9} \mathrm{CFU} / \mathrm{g}$, Coliforms từ $1,1 \times 10^{4}-1,5 \times 10^{8} \mathrm{MPN} / \mathrm{g}$ và $E$. coli nằm trong khoảng $1,1 \times 10^{2}-9,2 \times 10^{5} \mathrm{MPN} / \mathrm{g}$. Không phát hiện thấy sự hiện diện của Clostridium perfringens và Staphylococcus aureus trong số mẫu được kiểm tra.

Tư khóa: Clostridium perfringens, Coliforms, Escherichia coli, Staphylococcus aureus, sản phẩm thịt đã chế biến, tổng số vi sinh vật hiếu khí.

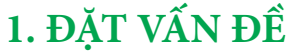

Trong những năm gân đây, với việc đẩy mạnh phát triển các công nghệ kỹ thuật hiện đại vào quy trình sản xuất, các sản phẩm thịt chế biến có sự đa dạng về chủng loại và số lượng hàng hóa ngày càng tăng đáp ứng được nhu cầu của người tiêu dùng. Tuy nhiên, bên cạnh những thuận tiện và tiềm năng của các sản phẩm thịt đã chế biến, tình hình gia tăng các trường hợp nhiễm độc thực phẩm do nhiêuu nguyên nhân như vi sinh vật, tôn dư hóa chất, mất vệ sinh tại các điểm bán hàng,... đã làm gia tăng mối lo ngại về an toàn vệ sinh thực phẩm. Theo báo cáo của Hội nghị trực tuyến toàn quốc về an toàn thực phẩm, năm 2019, toàn quốc ghi nhận 76 vụ ngộ độc thực phẩm làm gần 2.000 người mắc, 1.918 người nhập viện và 08 trường hợp tử vong [1]. Tại thành phố Huế, sản phẩm thịt đã chế biến là một trong những loại thực phẩm xuất hiện phổ biến và ngày càng nhiêu trong bữa ăn hàng ngày của người dân. Vì vậy, việc đánh giá mức độ ô nhiễm vi sinh vật trong sản phẩm thịt đã chế biến tại các chợ ở thành phố Huế nhằm cung cấp thêm thông tin về tình trạng nhiễm khuẩn cho các cơ quan quản lý và người tiêu dùng là rất cân thiết đối với thực trạng an toàn vệ sinh thực phẩm hiện nay. 


\section{VẬT LIỆU VÀ PHƯƠNG PHÁP NGHIÊN CỨU}

\section{1 Đối tượng nghiên cứu}

- Sản phẩm thịt đã chế biến bao gồm thịt chế biến không xử lý nhiệt (thịt lên men đại diện mẫu là nem chua) và thịt đã qua xử lý nhiệt (thịt đóng gói đại diện mẫu là chả lụa và không đóng gói đại diện mẫu là thịt heo luộc, thịt heo quay).

- Các nhóm vi sinh vật: Tổng số vi sinh vật hiếu khí (TSVSVHK), Coliforms, Escherichia coli, Clostridium perfringens, Staphylococcus aureus.

\subsection{Phương pháp nghiên cứu}

\subsubsection{Cổ mẫu sản phâm thực phâm và chọn mẫu}

Sử dụng công thức tính cỡ mẫu sau:

$$
n=\frac{z^{2} \cdot p \cdot(1-p)}{e^{2}}
$$

Trong đó:

- n: cỡ mẫu.

- z: độ tin cậy = 1,96.

- p: tỷ lệ ước đoán từ một nghiên cứu trước $=0,76$ (Nghiên cứu của Nguyễn Thuần Anh (2014), tỷ lệ mẫu thịt và các sản phẩm thịt đã chế biến chín, ăn liền nhiễm Coliforms là 76,2\%) [2].

- e: là độ chính xác mong muốn = 0,095.

Thực tế, trong quá trình nghiên cứu, chúng tôi đã phân tích 90 mẫu.

- Địa điểm thu mẫu: Một số chợ ở khu vực Nam sông Hương, thành phố Huế bao gồm chợ An Cựu, chợ Bến Ngự và chợ Hai Bà Trưng.

- Địa điểm phân tích: Trung tâm Kiểm nghiệm thuốc, mỹ phẩm, thực phẩm Thửa Thiên Huế.

\subsubsection{Phương pháp nghiên cứu}

\subsubsection{Chuân bị mẫu}

Cân tối thiểu $25 \mathrm{~g}$ của phân mẫu đại diện, sau đó bổ sung thêm $225 \mathrm{~mL}$ dung dịch đệm peptone $0,1 \%$ và tiến hành đồng nhất mẫu (dập bằng bagmixer trong 2 phút), thu được dịch mẫu với nông độ ban đâu $10^{-1}$. Lấy $1 \mathrm{~mL}$ ở dịch mẫu ban đầu cho vào ống nghiệm chứa $9 \mathrm{~mL}$ nước peptone $0,1 \%$, ta được dịch mẫu nồng độ $10^{-2}$. Pha loãng tương tự thành dãy pha loãng thập phân đến các nông độ $10^{-3}, 10^{-4}, 10^{-5}, \ldots[3]$.

\subsubsection{2. Định lượng vi sinh vật}

- Định lượng tổng số vi sinh vật hiếu khí theo TCVN 4884-1:2015 [4].

- Đinh lượng Coliforms theo TCVN 4882:2007 [5].

- Định lượng Escherichia coli theo TCVN 6846:2007 [6].

- Đinh lượng Clostridium perfrigens theo TCVN 4991:2005 [7].

- Định lượng Staphylococcus aureus theo TCVN 4830-3:2005 [8]. 


\subsubsection{Xủ lý số liệu}

Số liệu xử lý thống kê (theo Excel 2016) được dạng log để so sánh thống kê bằng phân tích phương sai (ANOVA) một nhân tố với mức ý nghĩa được chọn $\alpha \leq 0,05$, và đánh giá hệ số tương quan (Correlation).

\section{KẾT QUẢ VÀ THẢO LUẬN}

\subsection{Mức độ nhiễm khuẩn của các sản phẩm nghiên cứu}

\subsubsection{Tông số vi sinh vật hiếu khí}

Kết quả phân tính định lượng TSVSVHK trong sản phẩm thịt đã chế biến tại một số chợ ở khu vực Nam sông Hương, thành phố Huế được thể hiện qua Bảng 1.

Bảng 1. Kết quả dịnh lượng tông số vi sinh vật hiếu khí của sản phẩm thịt đã chế biến (CFU/g)

\begin{tabular}{|c|c|c|c|c|}
\hline Loại mẫ̂ & An Cưu & Bến Ngự & Hai Bà Truing & Giới hạn tối $d a[9]$ \\
\hline \multirow{10}{*}{$\begin{array}{l}\text { Thịt lên men } \\
\quad(n=10)\end{array}$} & $1,4 \times 10^{8}$ & $5,7 \times 10^{6}$ & $2,4 \times 10^{7}$ & \multirow{10}{*}{-} \\
\hline & $2,8 \times 10^{7}$ & $7,1 \times 10^{6}$ & $9,6 \times 10^{5}$ & \\
\hline & $7,1 \times 10^{8}$ & $8,0 \times 10^{6}$ & $2,9 \times 10^{6}$ & \\
\hline & $1,4 \times 10^{8}$ & $9,7 \times 10^{6}$ & $5,4 \times 10^{6}$ & \\
\hline & $1,4 \times 10^{8}$ & $1,2 \times 10^{7}$ & $5,7 \times 10^{6}$ & \\
\hline & $1,5 \times 10^{8}$ & $1,3 \times 10^{7}$ & $5,9 \times 10^{6}$ & \\
\hline & $2,1 \times 10^{8}$ & $1,8 \times 10^{7}$ & $5,9 \times 10^{6}$ & \\
\hline & $2,5 \times 10^{8}$ & $2,1 \times 10^{7}$ & $7,1 \times 10^{6}$ & \\
\hline & $2,7 \times 10^{9}$ & $2,9 \times 10^{7}$ & $8,5 \times 10^{6}$ & \\
\hline & $2,8 \times 10^{9}$ & $2,2 \times 10^{8}$ & $9,0 \times 10^{7}$ & \\
\hline \multirow{10}{*}{$\begin{array}{l}\text { Thịt đóng gói } \\
\quad(n=10)\end{array}$} & $2,1 \times 10^{6}$ & $3,6 \times 10^{5}$ & $2,7 \times 10^{3}$ & \multirow{10}{*}{$10^{4}$} \\
\hline & $2,4 \times 10^{6}$ & $2,2 \times 10^{8}$ & $4,0 \times 10^{5}$ & \\
\hline & $2,0 \times 10^{7}$ & $2,7 \times 10^{6}$ & $6,1 \times 10^{3}$ & \\
\hline & $1,1 \times 10^{7}$ & $7,7 \times 10^{5}$ & $1,7 \times 10^{5}$ & \\
\hline & $1,4 \times 10^{7}$ & $8,8 \times 10^{6}$ & $2,1 \times 10^{6}$ & \\
\hline & $1,8 \times 10^{7}$ & $8,9 \times 10^{6}$ & $3,3 \times 10^{5}$ & \\
\hline & $1,9 \times 10^{7}$ & $9,4 \times 10^{6}$ & $1,1 \times 10^{6}$ & \\
\hline & $2,4 \times 10^{7}$ & $9,7 \times 10^{6}$ & $1,4 \times 10^{5}$ & \\
\hline & $3,1 \times 10^{7}$ & $1,6 \times 10^{6}$ & $1,7 \times 10^{5}$ & \\
\hline & $5,8 \times 10^{7}$ & $2,2 \times 10^{5}$ & $1,9 \times 10^{5}$ & \\
\hline
\end{tabular}




\begin{tabular}{|c|c|c|c|c|}
\hline \multirow{10}{*}{$\begin{array}{l}\text { Thịt không đóng gói } \\
\qquad(n=10)\end{array}$} & $7,8 \times 10^{7}$ & $3,4 \times 10^{6}$ & $4,7 \times 10^{5}$ & \multirow{10}{*}{$10^{5}$} \\
\hline & $9,0 \times 10^{7}$ & $7,7 \times 10^{6}$ & $7,1 \times 10^{4}$ & \\
\hline & $9,4 \times 10^{8}$ & $8,7 \times 10^{6}$ & $8,0 \times 10^{6}$ & \\
\hline & $9,4 \times 10^{7}$ & $1,4 \times 10^{7}$ & $1,7 \times 10^{6}$ & \\
\hline & $1,0 \times 10^{7}$ & $1,9 \times 10^{7}$ & $1,8 \times 10^{5}$ & \\
\hline & $1,1 \times 10^{8}$ & $2,0 \times 10^{7}$ & $2,1 \times 10^{5}$ & \\
\hline & $6,2 \times 10^{8}$ & $2,0 \times 10^{7}$ & $2,2 \times 10^{5}$ & \\
\hline & $6,9 \times 10^{8}$ & $2,1 \times 10^{7}$ & $2,6 \times 10^{6}$ & \\
\hline & $2,5 \times 10^{8}$ & $2,6 \times 10^{7}$ & $4,6 \times 10^{6}$ & \\
\hline & $8,7 \times 10^{8}$ & $8,9 \times 10^{6}$ & $4,9 \times 10^{7}$ & \\
\hline
\end{tabular}

Ghi chú: (-): Không có quy định về giới hạn tối đa cho phép đối với TSVSVHK theo Quyết định 46/2007/QĐ-BYT [9].

Từ kết quả Bảng 1 cho thấy, TSVSVHK trong 90 mẫu khảo sát có sự biến động từ $2,7 \times 10^{3}$ đến $2,8 \times 10^{9} \mathrm{CFU} / \mathrm{g}$, với mẫu có mức độ nhiễm cao nhất là $2,8 \times 10^{9} \mathrm{CFU} / \mathrm{g}$ (sản phẩm thịt lên men) ở chợ An Cựu, thấp nhất là $2,7 \times 10^{3} \mathrm{CFU} / g$ (sản phẩm thịt đóng gói) ở chợ Hai Bà Trửng.

\subsubsection{Coliforms}

Kết quả phân tính định lượng Coliforms trong sản phẩm thịt đã chế biến được thể hiện qua Bảng 2.

Bảng 2. Kết quả định lượng Coliforms của sản phâm thịt đã chế biến (MPN/g)

\begin{tabular}{|c|c|c|c|c|}
\hline Loại mẫu & $A n C u ̛ u$ & Bến Ngự & Hai Bà Trüng & Giới hạn tối đa [9] \\
\hline \multirow{10}{*}{$\begin{array}{l}\text { Thịt lên men } \\
\quad(n=10)\end{array}$} & $1,1 \times 10^{5}$ & $1,2 \times 10^{4}$ & $1,5 \times 10^{4}$ & \multirow{10}{*}{50} \\
\hline & $3,9 \times 10^{4}$ & $2,1 \times 10^{5}$ & $4,3 \times 10^{4}$ & \\
\hline & $4,3 \times 10^{5}$ & $4,6 \times 10^{5}$ & $4,6 \times 10^{4}$ & \\
\hline & $1,1 \times 10^{7}$ & $1,1 \times 10^{6}$ & $1,1 \times 10^{5}$ & \\
\hline & $1,1 \times 10^{7}$ & $1,4 \times 10^{6}$ & $9,2 \times 10^{5}$ & \\
\hline & $2,0 \times 10^{7}$ & $1,5 \times 10^{6}$ & $1,1 \times 10^{6}$ & \\
\hline & $7,5 \times 10^{7}$ & $1,5 \times 10^{6}$ & $1,1 \times 10^{6}$ & \\
\hline & $9,3 \times 10^{7}$ & $2,4 \times 10^{6}$ & $1,4 \times 10^{6}$ & \\
\hline & $1,1 \times 10^{8}$ & $4,6 \times 10^{6}$ & $2,1 \times 10^{6}$ & \\
\hline & $1,5 \times 10^{8}$ & $2,4 \times 10^{7}$ & $2,4 \times 10^{6}$ & \\
\hline
\end{tabular}




\begin{tabular}{clll}
\hline & $2,2 \times 10^{4}$ & $1,1 \times 10^{4}$ & $1,1 \times 10^{4}$ \\
& $7,5 \times 10^{4}$ & $1,4 \times 10^{4}$ & $1,5 \times 10^{4}$ \\
& $9,3 \times 10^{4}$ & $1,5 \times 10^{4}$ & $2,0 \times 10^{4}$ \\
$1,1 \times 10^{5}$ & $1,5 \times 10^{4}$ & $2,4 \times 10^{4}$ \\
Thịt dóng gói & $4,6 \times 10^{5}$ & $1,5 \times 10^{4}$ & $3,1 \times 10^{4}$ \\
(n=10) & $1,2 \times 10^{6}$ & $2,2 \times 10^{4}$ & $4,3 \times 10^{4}$ \\
& $1,4 \times 10^{6}$ & $2,0 \times 10^{5}$ & $4,6 \times 10^{4}$ \\
& $1,5 \times 10^{6}$ & $2,1 \times 10^{5}$ & $4,6 \times 10^{4}$ \\
& $2,1 \times 10^{6}$ & $4,3 \times 10^{5}$ & $7,2 \times 10^{4}$ \\
& $2,4 \times 10^{6}$ & $7,5 \times 10^{5}$ & $2,1 \times 10^{5}$ \\
\hline Thịt không dóng gói & $2,4 \times 10^{5}$ & $3,9 \times 10^{4}$ & $4,2 \times 10^{4}$ \\
(n= 10) & $4,6 \times 10^{5}$ & $4,2 \times 10^{4}$ & $4,6 \times 10^{4}$ \\
& $9,3 \times 10^{5}$ & $4,6 \times 10^{4}$ & $4,6 \times 10^{4}$ \\
& $1,1 \times 10^{6}$ & $7,5 \times 10^{5}$ & $1,1 \times 10^{5}$ \\
& $3,6 \times 10^{6}$ & $7,5 \times 10^{5}$ & $1,1 \times 10^{5}$ \\
& $3,9 \times 10^{6}$ & $9,3 \times 10^{5}$ & $2,1 \times 10^{5}$ \\
& $4,3 \times 10^{6}$ & $1,1 \times 10^{6}$ & $2,3 \times 10^{5}$ \\
& $4,6 \times 10^{6}$ & $2,3 \times 10^{6}$ & $2,3 \times 10^{5}$ \\
$9,3 \times 10^{6}$ & $2,4 \times 10^{6}$ & $2,4 \times 10^{5}$ \\
& $3,9 \times 10^{5}$ \\
\hline
\end{tabular}

Qua Bảng 2 chúng tôi ghi nhận thấy Coliforms trong sản phẩm thịt đã chế biến có sự biến động từ $1,1 \times 10^{4} \mathrm{MPN} / \mathrm{g}-1,5 \times 10^{8} \mathrm{MPN} / \mathrm{g}$, với mẫu có mức độ nhiễm cao nhất là $1,5 \times 10^{8}$ $\mathrm{MPN} / \mathrm{g}$ (sản phẩm thịt lên men), thấp nhất là $1,1 \times 10^{4} \mathrm{MPN} / \mathrm{g}$ (sản phẩm thịt đóng gói).

\subsubsection{Escherichia coli}

Kết quả phân tính định lượng $E$. coli trong mẫu sản phẩm thịt đã chế biến được thể hiện qua Bảng 3.

Bảng 3. Kết quả dịnh lượng E. coli của sản phâm thịt đã chế biến (MPN/g)

\begin{tabular}{ccccc}
\hline Loại mẫu & An Cựu & Bến Ngự & Hai Bà Truing & Giới hạn tối đa [9] \\
\hline & $3,1 \times 10^{4}$ & $2,4 \times 10^{4}$ & $1,1 \times 10^{3}$ \\
$1,1 \times 10^{5}$ & $4,6 \times 10^{4}$ & $1,5 \times 10^{4}$ \\
$1,5 \times 10^{5}$ & $4,6 \times 10^{4}$ & $2,0 \times 10^{4}$ \\
& $2,1 \times 10^{5}$ & $1,1 \times 10^{5}$ & $2,2 \times 10^{4}$ \\
Thịt lên men & $2,1 \times 10^{5}$ & $1,2 \times 10^{5}$ & $2,3 \times 10^{4}$ \\
$(\mathbf{n}=\mathbf{1 0})$ & $2,2 \times 10^{5}$ & $1,5 \times 10^{5}$ & $4,3 \times 10^{4}$ \\
& $2,3 \times 10^{5}$ & $2,1 \times 10^{5}$ & $4,6 \times 10^{4}$ \\
& $2,4 \times 10^{5}$ & $4,6 \times 10^{4}$ & $7,5 \times 10^{4}$ \\
& $4,6 \times 10^{5}$ & $2,0 \times 10^{5}$ & $9,3 \times 10^{4}$ & \\
& $9,2 \times 10^{5}$ & $2,2 \times 10^{5}$ & $9,3 \times 10^{4}$ & \\
\hline
\end{tabular}




\begin{tabular}{clll}
\hline & $2,1 \times 10^{2}$ & $1,5 \times 10^{2}$ & $1,5 \times 10^{2}$ \\
$9,2 \times 10^{2}$ & $2,4 \times 10^{2}$ & $1,1 \times 10^{2}$ \\
$4,6 \times 10^{3}$ & $4,6 \times 10^{2}$ & $2,0 \times 10^{2}$ \\
& $7,5 \times 10^{3}$ & $4,6 \times 10^{3}$ & $2,4 \times 10^{2}$ \\
Thịt đóng gói & $1,5 \times 10^{3}$ & $1,1 \times 10^{3}$ & $2,3 \times 10^{3}$ \\
(n= 10) & $2,0 \times 10^{4}$ & $1,5 \times 10^{4}$ & $9,3 \times 10^{3}$ \\
& $3,9 \times 10^{4}$ & $7,5 \times 10^{4}$ & $1,2 \times 10^{4}$ \\
& $4,3 \times 10^{4}$ & $3,9 \times 10^{4}$ & $2,3 \times 10^{4}$ \\
& $3,9 \times 10^{5}$ & $2,4 \times 10^{4}$ & $4,6 \times 10^{4}$ \\
& $1,1 \times 10^{5}$ & $4,6 \times 10^{4}$ & $7,5 \times 10^{4}$ \\
\hline & $7,2 \times 10^{3}$ & $1,2 \times 10^{3}$ & $1,1 \times 10^{2}$ \\
Thịt không đóng gói & $1,4 \times 10^{3}$ & $1,5 \times 10^{4}$ & $9,2 \times 10^{2}$ \\
(n= 10) & $2,1 \times 10^{4}$ & $2,0 \times 10^{4}$ & $9,3 \times 10^{3}$ \\
& $9,3 \times 10^{4}$ & $2,1 \times 10^{4}$ & $1,5 \times 10^{4}$ \\
& $4,3 \times 10^{4}$ & $2,3 \times 10^{4}$ & $2,1 \times 10^{4}$ \\
& $7,5 \times 10^{4}$ & $2,4 \times 10^{4}$ & $2,3 \times 10^{4}$ \\
& $2,2 \times 10^{4}$ & $3,9 \times 10^{4}$ & $4,2 \times 10^{4}$ \\
& $4,6 \times 10^{4}$ & $4,3 \times 10^{4}$ & $4,6 \times 10^{4}$ \\
& $1,1 \times 10^{5}$ & $4,6 \times 10^{4}$ & $7,4 \times 10^{4}$ \\
$4,6 \times 10^{5}$ & $7,5 \times 10^{4}$ & $7,5 \times 10^{4}$ \\
\hline
\end{tabular}

Dựa vào kết quả Bảng 3 thấy rằng, số lượng $E$. coli ở 90 mẫu nghiên cứu có sự biến động từ $1,1 \times 10^{2}-9,2 \times 10^{5} \mathrm{MPN} / \mathrm{g}$, với mẫu có mức độ nhiễm cao nhất là $9,2 \times 10^{5} \mathrm{MPN} / \mathrm{g}$ (sản phẩm thịt lên men), thấp nhất là $1,1 \times 10^{2} \mathrm{MPN} / \mathrm{g}$ (sản phẩm thịt đóng gói).

\subsubsection{Clostridium perfringens và Staphylococcus aureus}

Kết quả phân tích cho thấy trong số 90 mẫu khảo sát không phát hiện thấy sự hiện diện của $C l$. perfringens và $S$. aureus. Tuy nhiên, trong quá trình phân tích mẫu, chúng tôi vẫn ghi nhận được sự phát triển của các khuẩn lạc thuộc chi Clostridium spp. và chi Staphylococcus spp. ở trong một số mẫu.

\subsubsection{Mức độ tương quan giũa ô nhiếm các nhóm vi sinh vật}

Khi nghiên cứu về mối tương quan giữa tỷ lệ nhiễm TSVSVHK với vi khuẩn Coliforms, E. coli, $\mathrm{Cl}$. perfringens và $S$. aureus trong các loại mẫu, kết quả thể hiện có sự tương quan rất chặt chẽ $(0,8 \leq \mathrm{r}<1)$ giữa các cặp chỉ tiêu: TSVSVHK và Coliforms $(\mathrm{r}=0,994)$, TSVSVHK và E. coli $(\mathrm{r}=0,979)$, Coliforms và E. coli $(\mathrm{r}=0,995)$.

Qua kết quả phân tích sự tương quan giữa hai cặp nhóm TSVSVHK và Coliforms, TSVSVHK và $E$. coli chỉ ra các sản phẩm nghiên cứu mặc dù có mức độ nhiễm TSVSVHK thấp, nhưng vẫn có sự hiện diện của vi khuẩn Coliforms và E. coli. Tương tự, với mối tương quan rất chặt chẽ $(\mathrm{r}=0,995)$, nguy cơ nhiễm đồng thời vi khuẩn Coliforms và $E$. coli của các sản phẩm nghiên cứu là rất cao.

Đối với vi khuẩn $C l$. perfringens và $S$. aureus, trong quá trình phân tích các sản phẩm nghiên cứu đều không phát hiện thấy sự phát triển của hai loài vi khuẩn này. Từ kết quả phân 
tích trên, chúng tôi thấy rằng mức độ nhiễm TSVSVHK, Coliforms và E. coli cao không chỉ điểm cho hai loại vi khuẩn $C l$. perfringens và S. aureus (Hình 3.1).

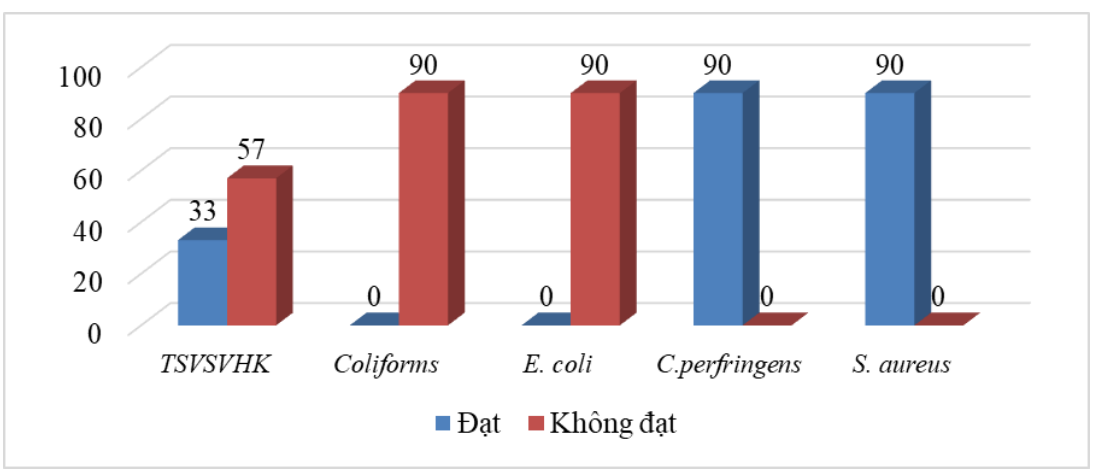

Hinh 1. Số lượng mẫu phân tích đạt tiêu chuân theo yêu cẩu của Bộ Y tế đối với tüng chỉ tiêu vi sinh vật

\section{2. Đánh giá mức độ nhiễm khuẩn của các sản phẩm thịt tại các chợ}

Tỷ lệ nhiễm vi sinh vật bao gồm TSVSVHK, Coliforms, E. coli, Cl. perfringens và S. aureus trên các sản phẩm thịt đã chế biến được trình bày ở Bảng 4 .

Bảng 4. Tỷ lệ nhiễm khuẩn của sản phâm thịt đã chế biến vể các chỉ tiêu vi sinh vật

\begin{tabular}{|c|c|c|c|c|}
\hline Chỉ tiêu vi sinh & Loại mẫu & $\begin{array}{c}\text { Số mẫu } \\
\text { nhiếm }\end{array}$ & $\begin{array}{l}\text { Số mẫu không } \\
\text { đạt tiêu chuẩn }\end{array}$ & $\begin{array}{c}\text { Tỷ lệ mẫu không đạt } \\
\text { tiêu chuân (\%) }\end{array}$ \\
\hline \multirow{4}{*}{ TSVSVHK } & Thịt lên men & 30 & - & - \\
\hline & Thịt đóng gói & 30 & 28 & 93,33 \\
\hline & Thịt không đóng gói & 30 & 29 & 96,67 \\
\hline & Tồng cộng & 90 & 57 & 63,33 \\
\hline \multirow{4}{*}{ Colifrorms } & Thịt lên men & 30 & 30 & 100 \\
\hline & Thịt đóng gói & 30 & 30 & 100 \\
\hline & Thịt không đóng gói & 30 & 30 & 100 \\
\hline & Tổng cộng & 90 & 90 & 100 \\
\hline \multirow{4}{*}{ E. coli } & Thịt lên men & 30 & 30 & 100 \\
\hline & Thịt đóng gói & 30 & 30 & 100 \\
\hline & Thịt không đóng gói & 30 & 30 & 100 \\
\hline & Tổng cộng & 90 & 90 & 100 \\
\hline \multirow{4}{*}{ Cl. perfringens } & Thịt lên men & 0 & 0 & 0 \\
\hline & Thịt đóng gói & 0 & 0 & 0 \\
\hline & Thịt không đóng gói & 0 & 0 & 0 \\
\hline & Tổng cộng & 0 & 0 & 0 \\
\hline \multirow{4}{*}{ S. aureus } & Thịt lên men & 0 & 0 & 0 \\
\hline & Thịt đóng gói & 0 & 0 & 0 \\
\hline & Thịt không đóng gói & 0 & 0 & 0 \\
\hline & Tổng cộng & 0 & 0 & 0 \\
\hline
\end{tabular}

Ghi chú: (-): Không có quy định vể giới hạn tối đa cho phép đối với TSVSVHK theo Quyết dinh 46/2007/QĐ-BYT [9]. 
So sánh kết quả nghiên cứu với Quyết định 46/2007/QĐ-BYT của Bộ Y tế về giới hạn tối đa cho phép đối với các chỉ tiêu vi sinh trong sản phẩm thịt đã chế biến, cho thấy:

- Về chỉ tiêu TSVSVHK, 57/60 mẫu nghiên cứu không đạt tiêu chuẩn của Bộ Y tế, chiếm 95\%. Đối với các sản phẩm thịt đóng gói và không đóng gói, khi so với kết quả nghiên cứu của tác giả Nguyễn Thuần Anh ở thành phố Nha Trang (2015) có tỷ lệ nhiễm TSVSVHK là 19,1\%, kết quả chúng tôi thu được là cao hơn rất nhiều [2].

- Về chỉ tiêu Coliforms, 100\% mẫu được khảo sát đều vượt giới hạn tối đa cho phép của Bộ Y tế. Chúng tôi nhận thấy kết quả này là cao hơn nhiêu so với kết quả nghiên cứu của tác giả Phạm Thị Ngọc Lan, Ngô Thị Tuyết Mai (2011) trên địa bàn thành phố Huế với tỷ lệ mẫu sản thịt chín không đạt tiêu chuẩn là 24,2\% [10].

- Về chỉ tiêu E. coli, 100\% mẫu phân tích đều vượt giới hạn tối đa cho phép của Bộ Y tế. Tỷ lệ này chênh lệch không đáng kể so với nghiên cứu của tác giả Ngô Thị Tuyết Mai (2011 2013) trên địa bàn thành phố Huế đối với nem (thịt lên men) là $86,7 \%$ và chả (thịt đóng gói) là 95,5\% [11]. Đối với thịt không đóng gói khi so sánh với nghiên cứu của Nguyễn Thuân Anh ở thành phố Nha Trang (2015) là 33,3\% và nghiên cứu của Phạm Thị Ngọc Lan (2011) trên địa bàn thành phố Huế là $42,4 \%$, thì kết quả của chúng tôi thu được cũng cao hơn rất nhiều $[2,10]$.

- 100\% mẫu nghiên cứu nằm trong giới hạn cho phép của Bộ Y tế đối với chỉ tiêu $C l$. perfringens và $S$. aureus và kết quả này thấp hơn so với kết quả nghiên cứu của tác giả Nguyễn Thuân Anh và cộng sự ở thành phố Nha Trang (2015) với tỷ lệ mẫu không đạt tiêu chuẩn của 02 loài vi khuẩn này là 4,8\% [2].

\section{KẾT LUẬN}

Kết quả nghiên cứu 90 sản phẩm thịt đã chế biến tại một số chợ ở khu vực Nam sông Hương thành phố Huế cho thấy: Tổng số vi sinh vật hiếu khí có số lượng dao động từ $2,7 \times 10^{3}$ - 2,8 $\times 10^{9} \mathrm{CFU} / \mathrm{g}$, trong đó 3,33\% mẫu nằm trong giới hạn tối đa cho phép đối với thịt và sản phẩm thịt theo Quyết định 46/2007/QĐ-BYT; Số lượng Coliforms dao động từ $1,10 \times 10^{4}-1,50$ $\times 10^{8} \mathrm{MPN} / \mathrm{g}$, số lượng $E$. coli dao động từ $1,10 \times 10^{2} \mathrm{MPN} / \mathrm{g}-9,20 \times 10^{5} \mathrm{MPN} / \mathrm{g}$, với 100\% mẫu vượt quá giới hạn tối đa cho phép đối với thịt và sản phẩm thịt theo Quyết định 46/2007/QĐBYT. $100 \%$ mẫu nghiên cứu không phát hiện thấy $\mathrm{Cl}$. perfringens và $\mathrm{S}$. aureus; và có mối tương quan rất chặt giữa các chỉ tiêu: tổng số vi sinh vật hiếu khí và Coliforms $(\mathrm{r}=0,994)$, tổng số vi sinh vật hiếu khí và $E$. coli $(\mathrm{r}=0,979)$, Coliforms và $E$. coli $(\mathrm{r}=0,995)$. Dựa trên những kết quả của nghiên cứu này, nhóm nghiên cứu kiến nghị tiếp tục mở rộng nghiên cứu trên nhiều địa điểm khác để có số liệu đầy đủ hơn về mức độ ô nhiễm vi sinh vật trong sản phẩm thịt đã chế biến tại các chợ ở thành phố Huế; đồng thời tiếp tục đánh giá thêm một số chỉ tiêu vi sinh vật khác đặc biệt là các nhóm vi sinh vật ảnh hưởng đến sức khỏe người tiêu dùng từ đó có thêm thông tin về tình trạng nhiễm khuẩn của các sản phẩm thịt đã chế biến tại các chợ ở thành phố Huế.

\section{TÀI LIỆ THAM KHẢO}

[1]. Bộ Y tế, Báo cáo của Bộ Y tế vê an toàn vệ sinh thực phẩm năm 2019, Hội nghị trực tuyến toàn quốc về an toàn thực phẩm, 2020.

[2]. Nguyễn Thuần Anh, "Đánh giá mức độ nhiễm vi sinh vật trong thực phẩm tại các hàng quán quanh Trường Đại học Nha Trang," Tạp chí Khoa học - Công nghệ Thủy sản, số 2/2015, tr. 3-8, 2015.

[3]. Bộ Khoa học và Công nghệ, TCVN 6404:2016 - Vi sinh vật trong thực phẩm và thức ăn chăn nuôi - Yêu cầu chung và hướng dẫn kiểm tra vi sinh vật, 2016.

[4]. Bộ Khoa học và Công nghệ, TCVN 4884-1: 2015 - Vi sinh vật trong chuỗi thực phâm - Phuiơng pháp định lượng vi sinh vật - Phân 1: Đếm khuân lạc ở 30 dị̂ C bằng kỹ thuật đỗ dĩa, 2015. 
[5]. Bộ Khoa học và Công nghệ, TCVN 4882:2007 - Vi sinh vật trong thực phẩm và thức ăn chăn nuôi - Phương pháp phát hiện và định lượng Coliform - Kỹ thuật đếm có số xác suất lớn nhất, 2007.

[6]. Bộ khoa học và Công nghệ, TCVN 6846:2007 - Vi sinh vật trong thực phẩm và thức ăn chăn nuôi - Phương pháp phát hiện và đinh lượng Escherichia coli giả định - Kỹ thuật đếm số có xác suất lớn nhất, 2007.

[7]. Bộ Khoa học và Công nghệ, TCVN 4991:2005 - Vi sinh vật trong thực phẩm và thức ăn chăn nuôi - Phương pháp dịnh lượng Clostridium perfrigens trên đĩa thạch - Kỹ thuật đếm khuân lạc, 2005.

[8]. Bộ Khoa học và Công nghệ, TCVN 4830-3:2005 - Vi sinh vật trong thực phẩm và thức ăn chăn nuôi - Phương pháp định luợng staphylococci có phản ứng duơng tính với coagulase (Staphylococcus aureus và các loài khác) trên dĩa thạch - Phân 3: Phát hiện và dùng kỹ thuật đếm số có xác suất lớn nhất (MPN) để đếm số lượng nhỏ, 2005.

[9]. Bộ Y tế, Quy định giới hạn tối đa ô nhiễm sinh học và hóa học trong thực phẩm, 2007.

[10]. Phạm Thị Ngọc Lan và Ngô Thị Tuyết Mai, "Khảo sát ô nhiễm vi sinh vật trong một số thực phẩm trên địa bàn thành phố Huế năm 2010-2011," Tạp chí Khoa học Đại học Huế, tập 73, số 4, tr. 66-67, 2012.

[11]. Ngô Thị Tuyết Mai, Đặng Văn Khánh, Phạm Thị Ngọc Lan, "Đánh giá mức độ nhiễm Escherichia coli trong một số thức ăn đường phố trên địa bàn thành phố Huế năm 20112013," Tạp chí Y học Thực hành, tập 933-934, số 59, tr. 181-184, 2014.

\title{
Assessment of microbiological contamination levels in processed meat products from markets in southern Hue city
}

\author{
Ton That Nhuan Than ${ }^{1}$, Ngo Thi Tuyet Mai', Pham Thi Ngoc Lan ${ }^{2}$ \\ ${ }^{1}$ Drug, Cosmetic and Food Quality Control Center, Thua Thien Hue Province, Vietnam \\ ${ }^{2}$ University of Sciences, Hue University, Vietnam
}

\section{Abstract}

Processed meat products are commonplace foods that are becoming increasingly popular in consumers' daily diets. Therefore, it is highly essential to assess the extent of microbiological contamination in the samples of processed meat products from markets in a bid to provide updated data of microbiological contamination to relevant agencies and local consumers as part of the current state of food safety and hygiene in the locality. A survey on microbiological contamination of processed meat products was conducted on samples collected from some markets in Southern Hue city. The 90 samples of three groups of fermented meat, packaged and non-packaged meat were analyzed. The results showed that, $100 \%$ of the samples were contaminated with aerobic microorganisms, Coliforms and Escherichia coli, in which 100\% of the samples of Coliforms and E. coli did not meet the quality norms set by the Ministry of Health. The total aerobic microorganisms, Coliforms and E. coli ranged from $2.7 \times 10^{3}$ to $2.8 \times 10^{9} \mathrm{CFU} / \mathrm{g}$, $1.1 \times 10^{4}$ to $1.5 \times 10^{8} \mathrm{MPN} / \mathrm{g}$ and $1.1 \times 10^{2}$ to $9.2 \times 10^{5} \mathrm{MPN} / \mathrm{g}$, respectively. No presence of Clostridium perfringens or Staphylococcus aureus was detected in the examined samples.

Keywords: Clostridium perfringens, Coliforms, Escherichia coli, processed meat products, Staphylococcus aureus, total aerobic microorganisms. 